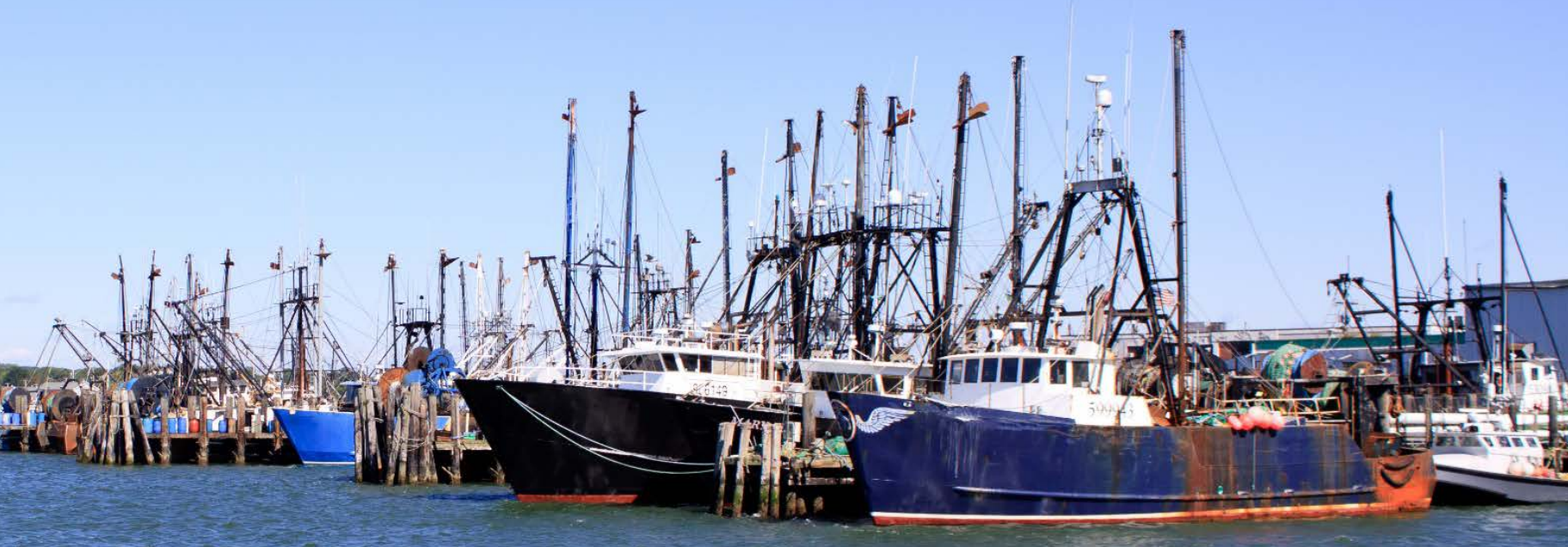

\title{
Addressing Interactions between Fisheries and Offshore Wind Development: The Block Island Wind Farm
}

May 2016

Prepared by

Andrew Lipsky, SeaPlan

Stephanie Moura, SeaPlan

Aileen Kenney, Deepwater Wind

Captain Rick Bellavance, Rhode Island Charter and Party Boat Association 


\section{Acknowledgements}

The authors gratefully acknowledge a number of individuals, organizations, and especially individual fishermen who contributed to the success of this project. We would particularly like to thank Captain Rodman Sykes and the crew of the F/V Virginia Marise, including "Uncle" Joe Waley, James Nelson, and Jerry Babcock for their input and guidance shared during the many hours fishing together as part of the collaborative fisheries monitoring. In addition, we thank Captain Lanny Dellinger and the crew of the F/V Megan and Kelsey and Captain Bill Mcelroy of the F/V Ellen June, who provided critical input and expert knowledge in the development of the project's lobster monitoring protocol. We wish to also thank SeaPlan staff Molly Morse and Ethan Machemer for their review and input into this report. The Commercial Fisheries Center of Rhode Island served as an important resource in coordinating fishing industry communication. We also gratefully acknowledge Dave Beutel of the Rhode Island Coastal Resources Management Council (CRMC) for his sage input into the design of collaborative monitoring programs. Rhode Island Department of Environmental Management's Mark Gibson and Nicole Lengyel and other marine fisheries staff provided valuable input and guidance into the design of the collaborative monitoring programs. We also acknowledge the contributions of CRMC's Fisheries Advisory Board and Habitat Advisory Board, which provided important review and input in the process.

Cover Photo Credits

Top: Fishing vessels at Point Judith, Rhode Island

Bottom: Foundation jackets of Block Island Wind Farm turbines (courtesy of Deepwater Wind, LLC) 


\section{TABLE OF CONTENTS}

Abstract

1

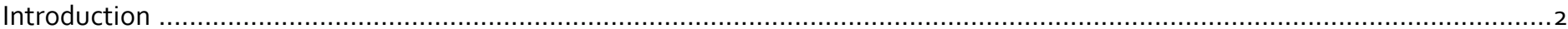

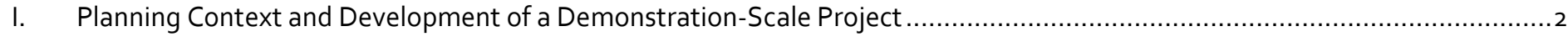

Addressing Fisheries Interactions in a Comprehensive Marine Spatial Planning Process ..............................................

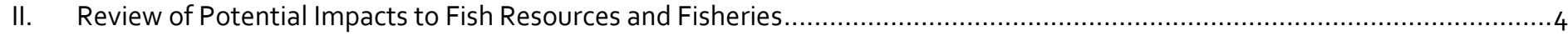

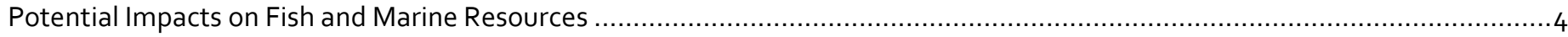

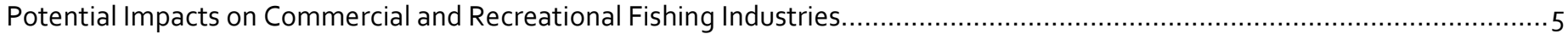

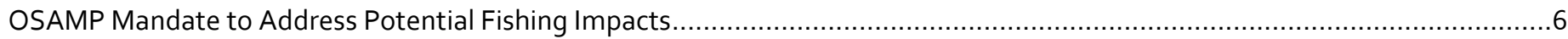

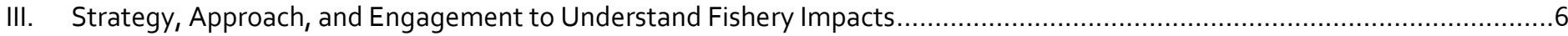

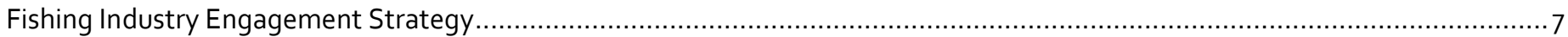

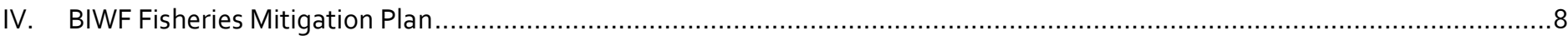

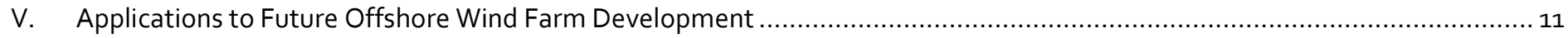

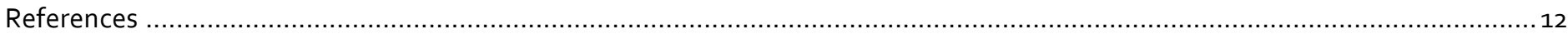




\section{ABSTRACT}

The Block Island Wind Farm (BIWF) is a 30-megawatt offshore wind farm located in Rhode Island waters approximately three miles southeast of Block Island. The BIWF consists of five offshore wind turbine generators and a submarine cable to Block Island. Deepwater Wind Block Island, LLC (DWBI), sited the BIWF within the Renewable Energy Zone established by the Rhode Island Coastal Resources Management Council (CRMC) through a well described comprehensive marine spatial planning process: the Ocean Special Area Management Plan (OSAMP; CRMC 2010). Construction of the BIWF began in 2015 and is scheduled for completion in 2016. When fully installed, the BIWF will generate over 125,000 megawatt hours of power annually, enough to satisfy 17,200 Rhode Island households (Tetra Tech 2012). Associated with the BIWF is the "seazshore: The Renewable Link" (seazshore; previously known as the "Block Island Transmission System"), a bi-directional cable system that will connect Block Island to the mainland electric grid for the first time.

Building off of work conducted as part of the OSAMP, DWBI made it a priority early in the project planning process to work with the commercial fishing industry, including recreational charter and party boat industries, to better understand potential impacts, minimize impacts, and develop mitigation measures. Starting in 2012, the DWBI team designed and initiated an outreach, impact minimization, and mitigation effort, the implementation of which is ongoing. Highlights of this effort include the following:

- Open meetings with the fishing community

- Meetings with the CRMC Fisheries Advisory Board (FAB)

- Meeting with individual fishing groups to discuss ways to avoid and minimize impact

- Establishment of fisheries and science liaisons

- An outreach and engagement process to inventory and evaluate potential fishery and fishing impacts

- Long-term collaborative groundfish and lobster studies with fishermen before, during, and after wind farm construction

- Development of a unique mitigation framework to address potential impacts

- A mitigation package that includes an innovative marketing campaign to promote charter and party boat fishing in Rhode Island and funding of an Executive Director of the Commercial Fisheries Center of Rhode Island

- A process to compensate fishermen impacted by closure of an area during foundation installation

This paper summarizes the fisheries outreach program and highlights strategies that were effective in minimizing conflict and establishing a collaborative relationship between DWBI and Rhode Island commercial and recreational fishing communities. As DWBI completes the BIWF construction and moves into the operations phase, lessons learned from the BIWF engagement model, mitigation framework, and collaborative data collection will be helpful to inform future offshore wind developments in the United States. 


\section{INTRODUCTION}

Estimates of potential energy production from offshore wind in the United States indicate that more than 1,000 gigawatts (GW) are available from Virginia to Maine (NREL 2010). To tap this potential and meet growing demand in the United States for new sources of renewable energy, offshore wind energy development is now underway along the Atlantic coast. In August 2015, Deepwater Wind Block Island, LLC (DWBI), began construction on the Block Island Wind Farm (BIWF), America's first offshore wind project. The BIWF is located in Rhode Island waters approximately three miles southeast of Block Island. Construction of the BIWF is scheduled to be finalized in 2016 and the wind farm is expected to come online by the end of 2016 .

The BIWF is a demonstration-scale project that precedes other planned offshore wind energy development along the outer continental shelf of the Atlantic coast. In southern New England, the federal Bureau of Ocean Energy Management (BOEM) has awarded four offshore renewable energy leases in BOEM-defined Wind Energy Areas (WEAs) located approximately 15 miles southwest of the BIWF. Two of these leases have been awarded to Deepwater Wind, LLC. The third is currently owned by Danish Oil and Natural Gas (DONG) and the fourth by Offshore MW, LLC. All of these projects are in the early stages of development and may benefit from the lessons learned at the BIWF.

With the growth of the offshore wind energy industry off the coast of southern New England, there are inherent tensions with the long-established commercial fishing industry. Because both industries rely on use of and access to ocean space and resources, effectively addressing their potential interactions is imperative to both fostering the offshore wind energy industry and continuing to sustain viable commercial fisheries.

This paper summarizes the BIWF fisheries outreach program and highlights strategies that were effective in minimizing conflict and establishing collaboration between DWBI and Rhode Island commercial and recreational fishing communities. In addition, this paper describes and provides insights on the process DWBI used to apply best practices in marine management and stakeholder engagement to address concerns and issues between offshore development and commercial fishing. This paper is organized into the following five sections:

\section{PLANNING CONTEXT AND DEVELOPMENT OF A DEMONSTRATION-SCALE PROJECT}

Presents a short summary of the government-led planning efforts prior to project inception that set an important context for DWBI's efforts to engage the commercial fishing industry.

\section{REVIEW OF POTENTIAL IMPACTS TO FISH RESOURCES AND FISHERIES}

Presents a review of pertinent literature on the potential impacts and effects of offshore wind energy on commercial fishing uses and related marine resource conditions to better understand the context of potential interactions between the offshore wind and fishing industries.

\section{STRATEGY, APPROACH, AND ENGAGEMENT TO UNDERSTAND FISHERY IMPACTS}

Outlines the strategy and approach undertaken by the DWBI team to address commercial fishing interests during the development and construction phases.

\section{BIWF FISHERIES MITIGATION PLAN}

Summarizes the tools and best practices that formed the basis of reaching agreement between the BIWF and the commercial and recreational fishing industries, with a focus on DWBI's development of a mitigation framework and employment of fisheries mitigation measures and particular emphasis on collaborative fisheries monitoring and impact assessment.

\section{APPLICATIONS TO FUTURE OFFSHORE WIND FARM DEVELOPMENT}

Describes how lessons learned from the BIWF can be applied to future commercial-scale wind energy developments.

\section{PLANNING CONTEXT AND DEVELOPMENT OF A DEMONSTRATION-SCALE PROJECT}

The BIWF resulted from a series of important actions taken by the Rhode Island government to promote the development of utility-scale renewable energy projects generally, and offshore wind specifically. In 2005, Rhode Island adopted into law a Renewable Energy Standard, which requires electric distribution companies to purchase $16 \%$ of their total electric load from renewable sources. In 2009, Rhode Island enacted the Long-Term Contracting Act, requiring local electric distribution companies to solicit longterm power purchase contracts for renewable energy, including a provision specifically calling for a utility-scale offshore wind energy project. 
Concurrent with these legislative actions, Rhode Island commissioned an energy policy study, entitled RI WINDS Phase I: Wind Energy Siting Study, to evaluate the potential for offshore wind development in state waters. Following the completion of this study, the governor of Rhode Island set a state policy goal of procuring $15 \%$ of the state's energy load from offshore wind. To implement this policy, the State conducted a competitive solicitation to select a preferred developer for offshore wind projects. Through this process, the State selected DWBI. As part of the agreement between DWBI and the state, and as required by subsequent legislation, DWBI agreed to develop a demonstration-scale offshore wind energy project off the coast of Block Island and a submarine transmission cable connecting Block Island to the Rhode Island mainland (Figure 1).

In 2011, DWBI submitted a number of applications to federal, state, and municipal authorities for the BIWF, including one to CRMC under the Rhode Island Ocean Special Area Management Plan (OSAMP). Ultimately, CRMC awarded DWBI a commercial lease for the BIWF. During the preparation of their application, DWBI completed a review of potential fisheries impacts and engaged in stakeholder outreach.
As a demonstration project, the BIWF has given both government and industry the opportunity to seek answers to the question, "How can we effectively plan, design, permit, and construct an offshore wind energy project on a pilotscale in order to apply key lessons to future commercial scale projects?" Within this construct, the BIWF's approach to addressing fisheries interactions offers considerable insight.

\section{ADDRESSING FISHERIES INTERACTIONS IN A COMPREHENSIVE MARINE SPATIAL PLANNING PROCESS}

With the goal of planning comprehensively for ocean uses, including offshore energy facilities, the CRMC conducted considerable outreach during the development of the OSAMP. Stakeholders included commercial and recreational fishing interests, the Narragansett Indian Tribe, marine and fisheries scientists, and other ocean users. The OSAMP was finalized in 2010 and adopted into law by the Rhode Island legislature.
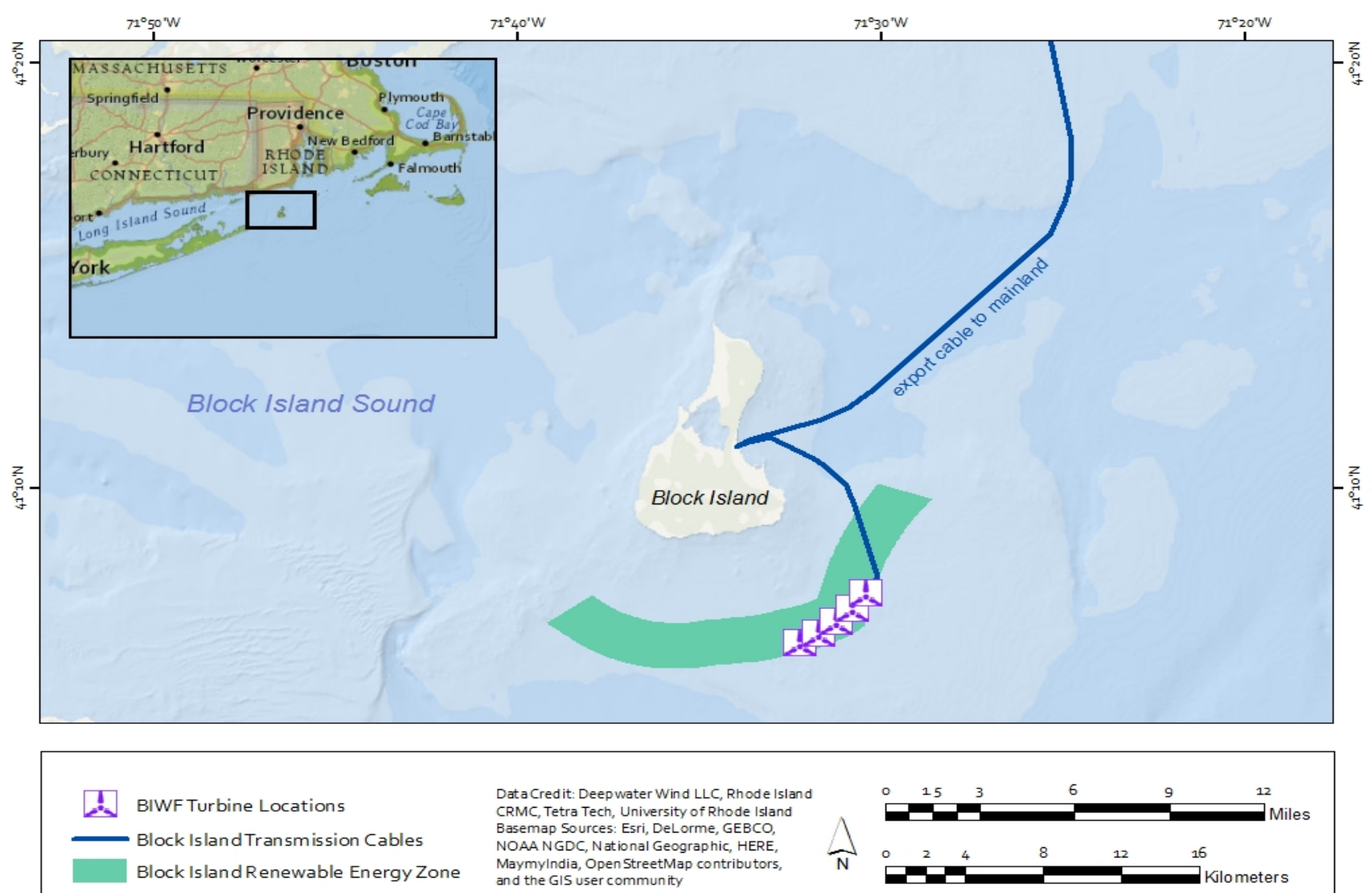

Figure 1. Location of the Block Island Wind Farm. 
Many stakeholders initially expressed concern over the prospect of an offshore wind energy project. The marine spatial planning process addressed this by using best available information about potential use conflicts and resource impacts to identify the most suitable area in the OSAMP boundary to designate as a Renewable Energy Zone (REZ). Given the importance of commercial and recreational fishing and the potential for interactions with offshore wind, there was extensive engagement of fishing interests to obtain their expert knowledge and input. This included assembling spatial data on commercial fishing activities through participatory mapping techniques (CRMC 2010). With spatial information on fishing, other uses, and natural resources, the OSAMP process ultimately identified a REZ off the coast of Block Island as the most suitable area for offshore wind.

In addition to the spatial designation of the REZ, the OSAMP includes specific regulatory requirements for "Large-scale Offshore Developments" with the potential to impact fisheries and fishing industries (OSAMP 2010). These requirements include consultation with the Fisheries Advisory Board (FAB; Section 1160.1.5), evaluation of potential adverse impacts on commercial and recreational fisheries (Section 560.2.3), development of mitigation plans (Section 560.2.4), and appointment of a fisheries liaison (Section 560.2.10). An important component of the OSAMP is the establishment of the $F A B$, which consists of representatives from the local fishing community to provide input, advice, and technical information related to industry issues and concerns. The OSAMP does not prescribe specific approaches, tools, or methodologies to be employed to meet these requirements.

\section{REVIEW OF POTENTIAL IMPACTS TO} FISH RESOURCES AND FISHERIES

The development of offshore wind energy has the potential to impact 1) fish and their marine habitats and 2) the commercial and recreational fishing industries that depend on these resources. Although some studies have investigated impacts during the construction and operations phases of offshore wind energy projects in Europe, the body of scientific research is limited, particularly in the United States. A review of the literature found only 11 studies (none of which were completed in the United States) that performed some form of monitoring on the impacts of offshore wind energy projects to fish and fisheries, which highlights the need to fill an important science and management gap. In this section we summarize relevant findings from the existing literature.

\section{POTENTIAL IMPACTS ON FISH AND MARINE RESOURCES}

Although the impacts of construction and operations of offshore wind energy projects to fish and marine resources have not been directly studied in the United States, this paper summarizes potential effects based on a review of technical reports, peer-reviewed articles, publications of United States federal agencies, and environmental assessment documentation. Impacts on fish and marine life from offshore wind energy have been attributed to the effects of sound, vibration, electromagnetic fields, alteration and changes in habitat composition, and changes in fishing practices (Michel et al. 2007). Taken individually, the effects of construction activity and operations may have specific observed positive or negative ecological outcomes, but collectively, the overall impact has been described as minimal, with some claiming slightly net positive results (Bergström et al. 2013, Lindeboom et al. 2011, Hoth et al. 2011, Reubens et al. 2014, Lange et al. 2010).

\section{SOUND AND VIBRATION}

The sound and vibration generated from pile driving during wind turbine foundation installation may temporarily cause direct, negative behavioral and physiological responses in certain species (Normandeau 2012). High sound pressure levels from pile driving may deter fish from breeding or spawning sites, and have been shown to trigger behavioral responses, such as changes in swimming speed or direction, in sole and cod (Mueller-Blenkle et al. 2010). However, pile driving may only be a factor at short ranges and in high wind conditions (Wahlberg and Westerberg 2005), and little is known about the exact, direct effects (Popper and Hastings 2009). During normal operations and maintenance, it is unclear whether the sound generated has ongoing biologically significant effects (Gill et al. 2012).

\section{ELECTROMAGNETIC FIELDS}

Electricity from offshore wind generation sites is transmitted to shore via submarine seafloor cables, which produce electromagnetic fields (EMF). There is evidence that some species utilize the earth's naturally occurring EMF for orientation and migration (Gill et al. 2014). EMF can play a role in some species' foraging behavior, and elasmobranchs (e.g., sharks, rays, skates) are particularly sensitive to its presence (Michel et al. 2007, Gill et al. 2014). There is not sufficient evidence that EMF from offshore wind generation sites during normal operations has the potential for persistent direct effects on marine species (Gill et al. 2014). In addition, research has shown that the high voltage direct current (HVDC) used in offshore wind energy transmission, unlike alternating current, does not create electromagnetic 
fields that present issues to marine life. Migration and navigation of fish, such as salmon, and marine mammals have been shown to be unaffected by in the presence of HVDC cables and fields (Walker 2001).

\section{HABITAT ALTERATIONS}

The habitat and ecosystem in and around offshore wind farms may be temporarily altered by the installation of infrastructure. Depending on sediment types and construction methods, there is a possibility of increased turbidity during installation of turbine foundations and trenching for submarine cables, which may temporarily disturb marine species, particularly benthic species (Michel et al. 2007, Lange et al. 2010, Rein et al. 2013). Temporary, direct impacts to benthic species may occur when construction equipment, such as jack-up-rigs or anchoring tackle from support vessels, make contact with the seafloor (Kaplan 2011). Post-construction, if suspended sediments are redeposited, turbidity reduced, and the habitat remains suitable, marine species may return to the impacted area (Michel et al. 2007).

Alterations in currents around installed infrastructure may lead to localized, persistent changes in sediment composition and grain size (Lange et al. 2010). Scouring, the removal of granular seabed material by hydrodynamic forces, has been addressed around monopile foundations in order to limit amounts of erosion (Langhamer 2012). Materials used to attenuate scouring effects include gravel and boulders, and the placement of this material may lead to potential indirect and persistent benefits to fishery and marine resources in the creation of new habitat (Hoth et al. 2011). Increased hard vertical substrate may provide habitat for a variety of colonizing organisms, which settle in succession beginning with diatoms and filamentous algae, followed by barnacles and a more diverse community (Langhamer 2012). Similar assemblages have been observed on offshore oil platforms and artificial reefs (Michel et al. 2007, Rein et al. 2013), which have the potential to attract species that may utilize structures for foraging and predator avoidance (Lindeboom et al. 2011). Structures can also increase habitat heterogeneity, leading to higher species diversity and short-term increases in abundance (Leonhard et al. 2011). Even in the relatively small footprint of monopile foundations and scour protection, benthic habitat can be permanently altered (Kaplan 2011).

\section{FISHERIES MANAGEMENT}

Fishery resources may be affected by management regimes altered in and around offshore wind farms; however, the United States Coast Guard has stated that it does not intend to impose restrictions on fishing. In cases where fishing access in or around a wind farm is limited, and fish utilize the wind farm area for refuge, fishing pressure on target species may be reduced (Michel et al. 2007). With increased habitat and reduced fishing pressure there is evidence of population spill-over into surrounding waters (Punt et al. 2009, Langhamer 2012).

In sum, construction and operation of offshore wind energy may have direct and indirect ecological effects on fishery and marine resources. Direct and indirect outcomes are defined by National Environmental Policy Act (NEPA) guidance as either caused by the action and occurring at the same time and place, or caused by the action and are later in time and removed in distance, though still foreseeable, respectively (NEPA 2011). There may be positive and negative, as well as temporary and long-term, ecological impacts associated with particular aspects of this power generation sector, though there is consensus in the literature that minimal overall effects or impacts are likely to occur.

POTENTIAL IMPACTS ON COMMERCIAL AND RECREATIONAL FISHING INDUSTRIES

Offshore energy development may interact with other ocean user groups, including commercial marine transportation, recreational boating, conservation interests, and military activity. Potential impacts to commercial and recreational fisheries, the focus of this paper, have not been studied directly in the United States. Based on a review of available literature, including federal publications, peer reviewed articles, project development and permit documentation, and studies primarily from Europe examining other ocean energy activities, the main user interactions identified include changes to species abundance and distribution during and after construction, loss of access to fishing grounds, navigation hazards, and loss or damage of gear (Ecology and Environment 2014). These interactions may result in direct or indirect outcomes with temporary or permanent effects on fisheries. Factors such as size and spacing of turbines, design of infrastructure, timing of activities, proximity to specific fishery resources, and access management regimes in and around offshore wind farms will determine how the development of this power generation sector may positively or negatively impact the commercial and recreational fishing industries (Ecology and Environment 2014).

Security zones established around active construction areas may temporarily limit or eliminate access for fishermen (Michel et al. 2007, Ecology and Environment 2014). Fishermen may experience a loss of access to fishing grounds or the need to alter transit routes to or from fishing grounds during this phase. Persistent impacts can arise from hazards to navigation that may result in an increased risk of collision with vessels or with fixed infrastructure (Michel et al. 2007). Other lasting impacts may stem from lost or damaged 
fishing gear from fouling on installed infrastructure, such as midwater trawls, gill nets, longlines, or fixed gear snagging on turbine foundations (Michel et al. 2007, Ecology and Environment 2014).

As discussed in the previous section, the introduction of sound and vibration during construction may have temporary, negative behavioral and physiological effects on fishery and marine resources. This, coupled with alterations in habitat and water quality, may cause temporary injury or dispersion to some species, which in turn may affect fishermen. On the other hand, habitat alteration, particularly from artificial reef and aggregation effects around turbine foundations and scouring mitigation, may have a persistent positive outcome for fisheries after construction, such as increased catchability (Michel et al. 2007, Ecology and Environment 2014, Wilhelmsson et al. 2006, Inger et al. 2009, Lindeboom et al. 2011), and may be observed within the bounds of a wind farm as well in surrounding waters due to spillover effects (Punt et al. 2009, Langhamer 2012). However, the increased catchability of some species due to aggregation effects could result in indirect impacts to fisheries.

\section{OSAMP MANDATE TO ADDRESS} POTENTIAL FISHING IMPACTS

The OSAMP identified similar potential offshore wind and commercial fisheries interactions as those outlined in the previous section. For the BIWF, the CRMC mandated that potential impacts to groundfish and lobster (including limited fishing access, potential change in species and community diversity, and sound disturbances) be addressed before they would approve a project under the OSAMP. Based on materials filed by DWBI and documents produced during CRMC review, these impacts are expected to primarily be limited to a three-month closure of the BIWF foundation installation work area to fishing. CRMC approved BIWF's requested closure and process of compensating impacted fishermen to mitigate the impact.

\section{STRATEGY, APPROACH, AND} ENGAGEMENT TO UNDERSTAND FISHERY IMPACTS

To understand, minimize, and ultimately avoid or mitigate potential impacts to fisheries, DWBI developed a strategy and approach to engaging the fishing industry that employed a number of standard principles and best practices. The marine ecosystem management and planning literature offers a variety of definitions, principles, and best practices regarding effective engagement (Pomeroy and Douvere 2008), communications and outreach, and onshore/offshore development practices (Ecology and Environment 2014, Fishing Liaison with Offshore Wind and Wet Renewables Group 2014, Interagency Ocean Policy Task Force 2009). Drawing from these sources, along with SeaPlan's 2015 report Options for Cooperation between Commercial Fishing and Offshore Wind Energy Industries (Moura et al. 2015), we distilled four guiding principles, briefly outlined below:

1. UTILIZING EFFECTIVE STAKEHOLDER ENGAGEMENT AND COMMUNICATION TECHNIQUES AND PRACTICES

- Initiating engagement early in project development

- Scheduling meetings at times fishermen are available

- Ensuring transparency in the process

- Ensuring parties are aware of the decision making process and that information and data are publicly available

2. VALUING AND UTILIZING

TRADITIONAL AND LOCAL EXPERT KNOWLEDGE

- Ensuring equal consideration and application of local expert knowledge to inform project characterization and decision making, including in the design of scientific project studies

3. USING COLLABORATIVE MONITORING MODELS AND BEST AVAILABLE SCIENCE TO FILL DATA GAPS AND DEVELOP TRUSTED DATA

- Conducting cooperative environmental monitoring with multiple interests: industry, scientists, and developers

- Collaboratively identifying and prioritizing data gaps

4. UNDERSTANDING TRADEOFFS AND MITIGATING IMPACTS ON THOSE MOST AFFECTED

- Evaluating project-related concerns following methods mutually agreed upon by interests that self-identify as impacted by a project or activity

- Using effective social science survey methods to gather information on stakeholder opinions and concerns

To date, DWBI has utilized a number of these principles in developing a BIWF engagement strategy to identify effective mitigation measures. This engagement strategy is described below. 
FISHING INDUSTRY ENGAGEMENT STRATEGY

DWBI employed a targeted strategy to engage the fishing industry, understand industry concerns, evaluate potential impacts, and develop mitigation measures. This strategy consisted of four components: ${ }^{1}$

\section{EARLY CONSULTATION WITH OSAMP HABITAT AND FISHERIES ADVISORY BOARDS}

Over a nine-month span (Jan. to Sept. 2012), DWBI met with the Habitat Advisory Board (HAB) and Fisheries Advisory Board (FAB) to scope and discuss ideas for addressing fisheries impacts. The FAB's suggestions included a longterm monitoring program for key Rhode Island groundfish and lobster fisheries to measure potential changes before and after construction and operations of the BIWF.

\section{ESTABLISHMENT OF A BIWF FISHERIES ENGAGEMENT AND SCIENCE TEAM}

DWBI established both fisheries engagement and science liaisons, whose cooperation with one another proved to be an important factor in the overall success of the BIWF fishery engagement program.

DWBI employed a respected local fisherman to serve as the Fisheries Liaison, whose role was to contribute to the development and implementation of fishing industry outreach by meeting regularly with industry members, soliciting input and comments on the project, and communicating information bilaterally between the industry and DWBI (information and feedback from local fishermen to DWBI and information regarding the BIWF to local fishermen). The Fisheries Liaison position differed from that of the third-party fisheries liaison, which as stipulated by the OSAMP, served in a similar capacity on behalf of the CRMC during the construction and operations phases of the project (discussed in Section IV).

DWBI also secured third party services ${ }^{2}$ through a science liaison, who provided impartial leadership in the design and execution of collaborative fisheries monitoring and research efforts, and contributed generally to the development and implementation of fishing industry outreach.

The integration between the fisheries engagement and science liaisons not only enhanced internal coordination within the BIWF team, but also enabled more effective collaboration with state and federal fisheries management scientists, academics, and fishing industry representatives in designing and implementing the fisheries monitoring efforts.

\section{INDUSTRY-TO-INDUSTRY ENGAGEMENT AND ROUNDTABLE DISCUSSIONS}

The BIWF team designed and executed an outreach plan to identify interests, concerns, and views on the potential impacts of the BIWF on the Rhode Island fishing industry. The outreach plan consisted of the following engagement efforts: facilitated meetings with fishermen, informational meetings between the DWBI and the fishing industry, meetings and communication between the DWBI Fisheries Liaison and fishermen, a fishing industry questionnaire, and follow-up telephone and in-person interviews.

\section{A DWBI Outreach Report from the spring of 2013} summarized the findings from the aforementioned industryto-industry engagement efforts, including key fishing industry concerns, recommendations for mitigation, and collaborative opportunities for the industries' successful coexistence (Kearns \& West 2013). Key recommendations from the Outreach Report are summarized in Figure 2.

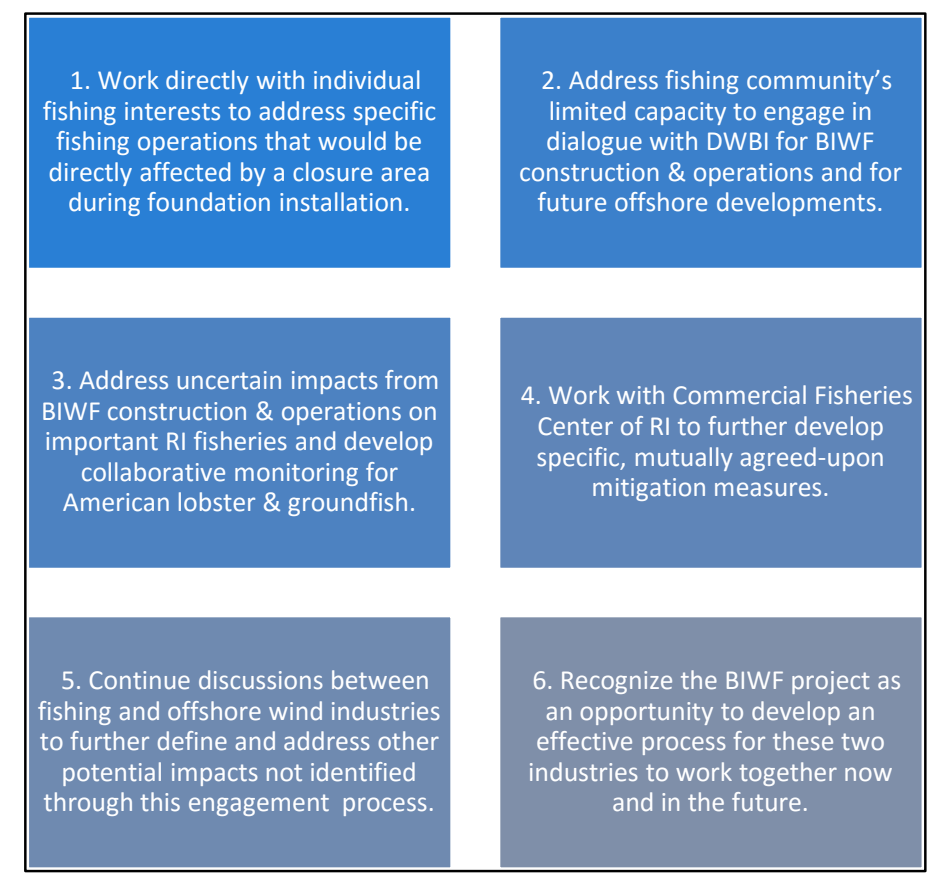

Figure 2. Key recommendations for mitigation and collaboration at BIWF (adapted from Kearns \& West 2013).

\footnotetext{
${ }^{1}$ It should be noted that these efforts were carried out in tandem with the regulatory permitting phases of the project and continued up to and through the construction phase of the project (July 2015 to present).
}

2 SeaPlan senior scientist 
To capitalize on the utility of these engagement efforts, industry roundtable discussions served as supplemental forums for identifying further options to minimize impacts and for defining, developing, and reaching final agreement on a mitigation framework.

\section{DEVELOPMENT OF MITIGATION}

\section{OPTIONS FRAMEWORK AND PLAN}

Building on the shared understanding established to date, the parties were well-positioned to develop a more detailed Fisheries Mitigation Options Framework. DWBI then worked with representatives of different gear types and the Commercial Fisheries Center of Rhode Island (CFCRI), as well the Rhode Island Department of Environmental Management (RIDEM) and the CRMC, to develop projectspecific mitigation measures. DWBI supported these discussions through additional facilitation, research, and fact-finding.

Fishing industry members and government scientists provided technical input into designing specific mitigation actions. For example, the parties developed a detailed collaborative monitoring program to address impacts to American lobster, a measure which had been agreed upon conceptually during 2012 outreach. Significant industry-toindustry facilitation, scientific analysis, and negotiations were required to design a robust monitoring protocol and to launch sampling efforts coincident with seasonally important lobster activity at least two years prior to start of construction.

The overall multi-step outreach and engagement process, outlined in Figure 3, supported industry-to-industry dialogue and generated information that ultimately enabled the parties to develop a mitigation agreement to address remaining impacts that could not be avoided. In late 2013, the resulting Mitigation Plan was approved by the CRMC and its execution was included as a stipulation of the BIWF CRMC Assent.

\section{BIWF FISHERIES MITIGATION PLAN}

The BIWF Fisheries Mitigation Plan is comprised of seven mitigation measures. These are outlined below, along with indications of how each measure reflects the guiding principles referenced in Section III (noted in italics). This section pays particular attention to the collaborative monitoring program, which has been regarded by participants from both industries as a foundational element of the Mitigation Plan.

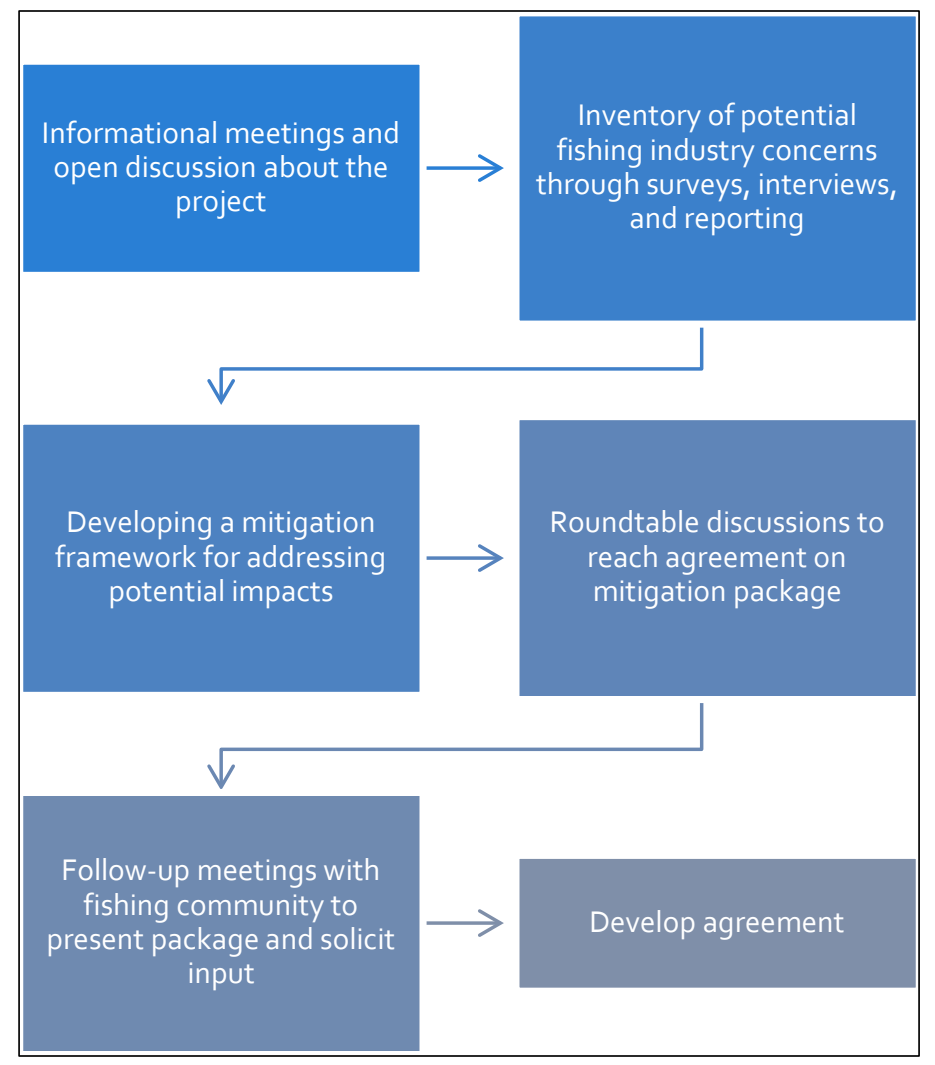

Figure 3. Process steps for industry-to-industry engagement of commercial fishing and offshore wind energy industries at BIWF.

\section{ONGOING OUTREACH BETWEEN OFFSHORE WIND AND FISHING INDUSTRIES}

Following the successful approach to engaging the commercial fishing industry in structured industry-toindustry discussions, this measure continues the ongoing dialogue between the two industries through regularlyscheduled open meetings held in locations close to Rhode Island fishing ports. This measure implements the principle of effective stakeholder engagement and communication.

\section{FUNDING OF A THIRD-PARTY FISHERIES LIAISON}

The funding of a third-party fisheries liaison is a requirement in the OSAMP (Sections 560.2.10 and 1160.7.6). The thirdparty fisheries liaison is required to have knowledge and understanding about fisheries, and his or her role is to facilitate direct communication between commercial and recreational fishermen and DWBI. Commercial fishermen have regular contact with and direct access to the fisheries liaison throughout all stages of the project: pre-construction, construction, operations, and decommissioning. This measure implements the principle of effective stakeholder engagement and communication. 


\section{COLLABORATIVE GROUNDFISH AND} LOBSTER MONITORING SURVEY

This mitigation measure describes the commitment by the developer to fund over $\$ 1.3$ million in fisheries impact studies to fill gaps in the understanding of potential impacts of offshore wind construction and operations for two key Rhode Island fisheries: American lobster (Homarus americanus) and groundfish. The two multi-year surveys were designed collaboratively by the BIWF science team and commercial fishermen, with significant input, review, and concurrence by state and federal fisheries authorities to ensure the studies would result in both "trusted" data and robust methods acceptable to state and federal resource managers and the scientific community. The surveys are executed on Rhode Island-based commercial fishing vessels staffed by a combination of fishermen and scientists (Figure 4).

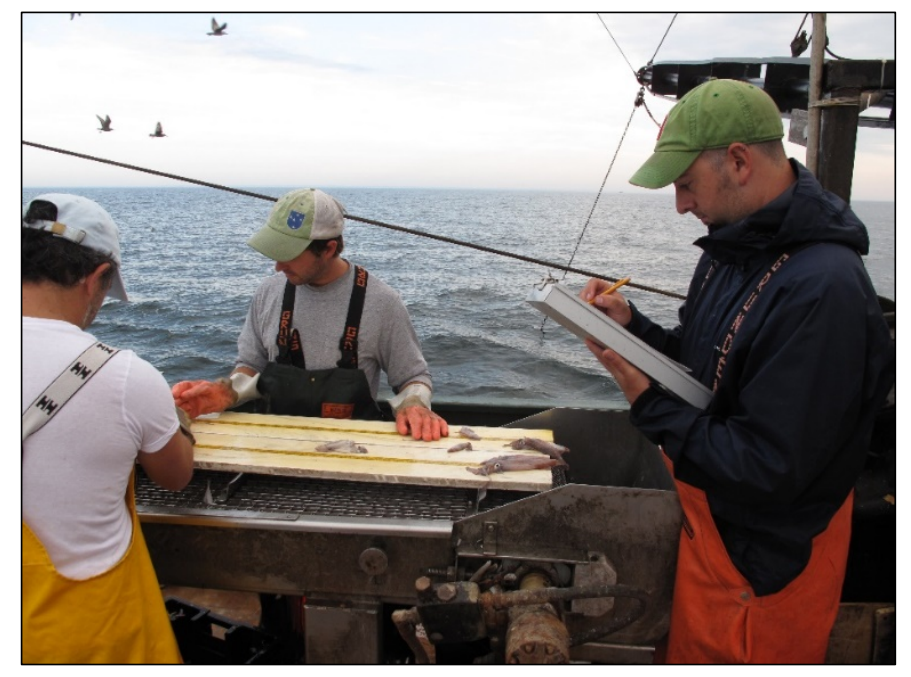

Figure 2. Researchers on board F/V Virginia Marise implement collaborative studies on groundfish populations near Block Island.

Based on early input from the $F A B$ and affirmation through fishing industry outreach, two specific fisheries were selected for impact studies-American lobster and groundfish (or demersal) fisheries-reflecting their importance to the local economy and livelihoods of Rhode Island fishermen. The studies required development of collaborative monitoring protocols for a ventless trap lobster survey and a groundfish survey trawl. Informed by fisheries experts in the region, BIWF's science liaison led the effort to establish the necessary science teams for designing the study programs, and led the subsequent execution of sampling activities in partnership with commercial fishing operations.

Using engagement strategies similar to the outreach process described in Section III, the two respective study design teams consulted with scientists, fishing industry representatives from the two focal sectors, and resource managers to develop the study methodologies. Numerous formal and informal meetings were convened for a variety of purposes, including developing study design options, addressing issues of conflict, obtaining expert knowledge, and ensuring accurate understanding of commercial fishing interests. Formal venues included the offices of DWBI, the CRMC, RIDEM, and the CFCRI. Additional meetings took place in the wheel houses of fishing vessels and at fishing docks. These processes guided the groundfish survey design during the summer of 2012 and the lobster survey design during the winter of 2013.

Obtaining fishing industry input for developing the survey protocols required spending significant time with fishermen to accurately understand individuals' interests and concerns, and to clearly articulate them into the language of scientific inquiries. Applying the fishing industry's expert local knowledge of fisheries and marine environmental conditions was vital to improving sampling procedures and survey design, as well as to the team's capabilities to implement the surveys over long time frames.

The BIWF science team also incorporated agency and academic input and guidance to ensure that study methods were compatible with and complementary to current state and regional fisheries monitoring approaches and employed standardized sampling procedures accepted by government and academic fisheries scientists. Coordinating with state fisheries managers at RIDEM Marine Fisheries and receiving CRMC fisheries expertise were critical in the development of survey protocols.

This collaborative monitoring component of the Mitigation Plan reflects both industry and governmental aspirations of using the BIWF as a demonstration project to apply learning and inquiry to the new and emerging field of offshore renewable energy management. Detailed descriptions of the resulting groundfish and lobster survey protocols can be found in CoastalVision and Seaplan (2012) and CoastalVision and SeaPlan (2013), respectively, and summary descriptions of the studies are provided in Figure 5. This measure implements the principles of effective stakeholder engagement and communication, valuing and utilizing traditional and local expert knowledge, and using collaborative monitoring models and best available science to fill data gaps and develop high quality and trusted data.

\section{LOCAL HIRING}

DWBI committed to hiring local fisherman to fill positions suitable to their qualifications to the greatest extent possible during construction of the project. In addition, DWBI supports a number of fishing operations that are involved in the collaborative fisheries monitoring programs. This measure implements the principle of understanding tradeoffs and mitigating impacts on those most affected. 
OVERVIEW OF DESIGN FOR BIWF

GROUNDFISH AND AMERICAN LOBSTER

VENTLESS TRAP SURVEYS

\section{GROUNDFISH MONITORING SURVEY}

This study consists of a multi-year trawl survey to characterize possible effects of the construction and operation of the BIWF on demersal fisheries. This cooperative monitoring program is carried out in partnership with the F/V Virginia Marise led by Captain Rodman Sykes. The survey has involved sampling on a monthly basis from September 2012 through June 2015 before construction was initiated, one year during bottom-disturbing construction activities (July 2015 through June 2016), and two years after construction (July 2016 through July 2018). The survey is structured with a before, after, control, impact design (BACl).

\section{AMERICAN LOBSTER VENTLESS TRAP SURVEY}

This study consists of a multi-year program to characterize possible effects of the construction and operation of the BIWF on American lobster. The survey similarly follows a BACl study design for direct physical disturbance effects, and a before/after study design for indirect noise effects at two distance intervals ( $0.2 \mathrm{~km}$ and $2 \mathrm{~km}$ Nearfield) from the BIWF wind turbine array construction impact area and at two Farfield Reference Areas for six months each of two years before and one year after construction. The study also consists of a single year control/impact study, implemented for six months during the year of construction, to characterize changes in local lobster abundance at two distance intervals from the construction area and at two Farfield Reference areas. The survey will also map spatially explicit lobster abundance and distribution for each year of the study within the three distance intervals surveyed $(0.2 \mathrm{~km}$, $2 \mathrm{~km}$ and the Farfield areas at $22 \mathrm{~km}$ from the construction impact area).

Figure 5. Overview of BIWF groundfish and lobster studies.

5. FUNDING OF AN EXECUTIVE DIRECTOR OF CFCRI TO PROVIDE INDUSTRY CAPACITY AND REPRESENTATION

Based on recommendations from the industry outreach process, DWBI's funding of an Executive Director of CFCRI has been a key aspect in building a trusted partnership between the two industries. The role of the Executive Director is similar in scope to a Fisheries Representative, identified by BOEM (2015) and utilized in other offshore developments in Northern Europe to serve a vital role in building capacity for the fishing community at large to engage directly with offshore wind developers. The
Executive Director of the CFCRI might also address other fishery management issues that may be important to the collective fishing industry group.

DWBI agreed to fund a candidate search and to fund the position for a period of four years. The Executive Director of CFCRI began working in March 2016. This measure implements the principle of effective stakeholder engagement and communication.

\section{AGREEMENT WITH THE RHODE ISLAND CHARTER BOAT ASSOCIATION TO SUPPORT MARKETING CAMPAIGN}

This mitigation measure was developed to address the potential indirect impacts of the project to the charter and party boat industry associated with the three-month closure of the Area of Potential Effect/Work Area. The measure involves funding a marketing campaign led by the Rhode Island Charter and Party Boat Association to enhance the visibility and market of commercial charter and party boat fishing in Rhode Island. This measure implements the principle of understanding tradeoffs and mitigating impacts on those most affected.

\section{PACKAGE TO OFFSET COMMERCIAL IMPACT OF THE BIWF WORK AREA CLOSURE}

DWBI, in consultation with CRMC, RIDEM, and the FAB, developed a plan to address direct impacts resulting from the three-month closure of the BIWF work area during foundation installation. DWBI agreed to establish and execute a compensation process for affected fishing interests. This process included three steps:

1. A Steering Committee was formed with one representative from each of the following entities: CFCRI, CRMC, RIDEM, FAB, and DWBI

2. The Steering Committee established an application and review process for claims

3. Applications are reviewed for accuracy and completeness in accordance with the process, and appropriate mitigation is determined and distributed to impacted fishermen

This measure implements the principle of understanding tradeoffs and mitigating impacts on those most affected. 
V. APPLICATIONS TO FUTURE OFFSHORE WIND FARM DEVELOPMENT

As America's first offshore wind farm, the BIWF has represented an important milestone for advancing offshore renewable energy. The outreach, communication, and engagement approaches; mitigation framework; and mitigation measures developed for this pilot project have helped to increase the level of cooperation between an emerging offshore wind industry and traditional commercial and recreational fishing industries.

While the OSAMP process established important underpinnings for applying best practices in marine ecosystem management, in 2012-prior to initiation of the BIWF's industry-to-industry engagement efforts-members of the Rhode Island fishing community had voiced concerns with regards to the pilot project moving forward. However, after nearly two years of work invested by members of these two industries to better understand project concerns, impacts, and options for mitigation, DWBI and fishing industry interests reached agreement. The process to reach an agreement as described in this paper helped establish trust and built the necessary social capital for members of these two industries to work together effectively. During the CRMC permit review hearings held in 2014, multiple members of the fishing industry testified in support of the BIWF and recommended that it be granted the requisite state approvals, which demonstrates the merit of the project as a model for future offshore developments.

In July 2015, the collaborative monitoring program hit an important project milestone by completing baseline preconstruction monitoring for the groundfish and lobster surveys, which have been conducted in cooperation with Rhode Island commercial fishermen. In July 2015, the $35^{\text {th }}$ monthly groundfish trawl survey-which is conducted one day per month for every month of the year-was completed, and in May 2015, the lobster survey-which is conducted monthly for six months out of the year-entered its third year of surveying. Collaborative data ventures and partnerships may be the most effective means of developing the trusted data necessary to understanding the interactions between industries and the impacts on the ecosystem resources. These studies will help both industries understand the potential positive, negative, or neutral impacts of offshore wind on important fisheries and will help inform future efforts to develop larger-scale projects off the coasts of Massachusetts and Rhode Island, which in early 2016 are in the pre-development phases.

In addition to collaborative data ventures between industries and government, a key lesson learned from the BIWF has been the utility of effective industry-to-industry dialogue within the context of a well-constructed management structure (e.g., FAB), as established by the OSAMP. The industry-to-industry roundtables served as an effective vehicle for clarifying respective needs and concerns and identifying ways to minimize conflict, mitigate impacts, and generate options for mutually beneficial cooperation.

As the BIWF finalizes construction in 2016 and transitions into the operations phase, the results of the mitigation measures now being implemented and data from the collaborative studies will be helpful toward improving state and federal ocean management activities and informing future offshore wind developments.

\footnotetext{
a
} 


\section{REFERENCES}

Bergström, L., Sundqvist, F. and Bergström, U. 2013. Effects of an offshore wind farm on temporal and spatial patterns in the demersal fish community. Marine Ecology Progress Series. 485. p. 199-210.

Bureau of Ocean Energy Management (BOEM). 2015. Guidelines for Providing Information on Fisheries Social and Economic Conditions for Renewable Energy Development on the Atlantic Outer Continental Shelf Pursuant to 30 CFR Part 585.

CoastalVision, LLC and SeaPlan. 2012. Deepwater Wind Block Island Wind Farm Final Trawl Survey Plan. Newport, RI.

CoastalVision, LLC and SeaPlan. 2013. Deepwater Wind Block Island Wind Farm Revised Draft Ventless Trap Survey Plan. Newport, RI.

CRMC. 2010. Rhode Island Ocean Special Area Management Plan (OSAMP). Wakefield, RI, USA.

Ecology and Environment, Inc. 2014. Development of Mitigation Measures to Address Potential Use Conflicts between Commercial Wind Energy Lessees/Grantees and Commercial Fishermen on the Atlantic Outer Continental Shelf Report on Best Management Practices and Mitigation Measures. A final report for the United States Department of the Interior, Bureau of Ocean Energy Management, Office of Renewal Energy Programs, Herndon, VA. OCS Study BOEM 2014-654. 98 p.

Fishing Liaison with Offshore Wind and Wet Renewables Group. 2014. Best Practice Guidance for Offshore Renewables Developments: Recommendations for Fisheries Liaison. The Crown Estate, Edinburgh, UK. 74 p.

Gill, A. B., Bartlett, M. and Thomsen, F. 2012. Potential interactions between diadromous fishes of UK conservation importance and the electromagnetic fields and subsea noise from marine renewable energy developments. Journal of Fish Biology. 81(2). p. 664-695.

Gill, A. B., Gloyne-Phillips, I., Kimber, J. and Sigray P. 2014. Marine Renewable Energy, Electromagnetic (EM) Fields and EM-Sensitive Animals. In: Shields, M. A. and Payne, A. I. L., eds., Marine Renewable Energy Technology and Environmental Interactions, $1^{\text {st }}$ ed. Springer Netherlands. p. 61-79.

Hoth, T., Dietrich, R., Reckordt, M. and Hartmann M. 2011. Impacts on demersal fish communities in the North Sea based upon data from the first German offshore wind farm. In: May, R. and Bevanger, K., eds. Proceedings. Conference on Wind Energy and Wildlife Impacts, 2-5 May 2011, Trondheim, Norway. NINA Report 693. $140 \mathrm{p}$.

Hvidt, C. B., Leonhard, S. B., Klaustrup, M. and Pedersen, J. 2006. Hydroacoustic Monitoring of Fish Communities at Offshore Wind Farms. Bio/consult as, Carl Bro as, and SIMRAD AS. 54 p.

Inger, R., Attrill, M. J., Bearhop, S., Broderick, A. C., Grecian, W. J., Hodgson, D. J., Mills, C., Sheehan, E., Votier S. C., Witt, M. J. and Godley, B. J. 2009. Marine renewable energy: potential benefits to biodiversity? An urgent call for research. Journal of Applied Ecology. 46. p. 1145-1153.

Kaplan, B., ed. 2011. Literature Synthesis for the North and Central Atlantic Ocean. United States Dept. of the Interior, Bureau of Ocean Energy Management, Regulation and Enforcement, Gulf of Mexico OCS Region, New Orleans, LA. OCS Study BOEMRE 2011-012. 447 P.

Kearns \& West, Inc. 2013. Summary Report: Deepwater Wind Outreach to the Rhode Island Fishing Community October/November 2012: Identification of Interests, Concerns, and Views Regarding Impacts to the Rhode Island Fishing Industry from the Block Island Wind Farm and Transmission System. Report prepared for Deepwater Wind and the Rhode Island Fishing Community. 13 p.

Lange, M., Burkhard, B., Garthe, S., Gee, K., Kannen, A., Lenhart, H. and Windhorst, W. 2010. Analyzing Coastal and Marine Changes: Offshore Wind Farming as a Case Study. Zukunft Küste - Coastal Futures Synthesis Report. LOICZ Research \& Studies No. 36. GKSS Research Center, Geesthacht, 212 p.

Langhamer, O. 2012. Artificial reef effect in relation to offshore renewable energy conversion: state of the art. The Scientific World Journal. 2012. 8 p.

Leonhard, S. B.; Stenberg, C. and Støttrup, J. (Eds.) 2011. Effect of the Horns Rev 1 Offshore Wind Farm on Fish Communities. Follow-up Seven Years after Construction. DTU Aqua, Orbicon, DHI, NaturFocus. Report commissioned by The Environmental Group through contract with Vattenfall Vindkraft A/S.

Lindeboom, H. J. Kouwenhoven, H. J., Bergman, M. J. N., Bouma, S., Brasseur, S., Daan, R., Fijn, R. C., de Haan, D., Dirksen, S., van Hal, R., Hille Ris Lambers, R., ter Hofstede, R., Krijgsveld, K. L., Leopold, M. and Scheidat, M. 2011. Short-term ecological effects of an offshore wind farm in the Dutch coastal zone; a compilation. Environmental Research Letters. 6.13 P. 
Michel, J., Dunagan, H., Boring, C., Healy, E., Evans, W., Dean, J.M., McGillis, A. and Hain, J. 2007. Worldwide Synthesis and Analysis of Existing Information Regarding Environmental Effects of Alternative Energy Uses on the Outer Continental Shelf. United States Department of the Interior, Minerals Management Service, Herndon, VA, MMS OCS Report 2007-038. 254 p.

Moura, S., Lipsky, A. and Morse, M. 2015. Options for Cooperation between Commercial Fishing and Offshore Wind Energy Industries: A Review of Relevant Tools and Best Practices. SeaPlan.

Mueller-Blenkle, C., McGregor, P. K., Gill, A. B., Andersson, M. H., Metcalfe, J., Bendall, V., Sigray, P., Wood, D. T. and Thomsen, F. 2010. Effects of Pile-driving Noise on the Behaviour of Marine Fish. COWRIE Ref: Fish 06-08, Technical Report. 62 p.

National Environmental Policy Act (NEPA). 40 C.F.R. \1508.8. 2011.

Normandeau Associates, Inc. 2012. Effects of Noise on Fish, Fisheries, and Invertebrates in the United States Atlantic and Arctic from Energy Industry Sound-Generating Activities. A Literature Synthesis for the United States Dept. of the Interior, Bureau of Ocean Energy Management. Contract \# M11PCo0031. 153 p.

Pomeroy, R. and Douvere, F. 2008. The engagement of stakeholders in the marine spatial planning process. Marine Policy. 32. p. 816-822.

Popper, A. N. and Hastings, M. C. 2009. The effects of anthropogenic sources of sound on fishes. Journal of Fish Biology. 75. p. 455-489.

Punt, M. J., Groeneveld, R. A., van lerland, E. C. and Stel, J. H. 2009. Spatial planning of offshore wind farms: a windfall to marine environmental protection? Ecological Economics. 69 (1). p. 93-103.

Rein C. G., Lundin, A. S., Wilson, S. J. K. and Kimbrell, E. 2013. Offshore Wind Energy Development Site Assessment and Characterization: Evaluation of the Current Status and European Experience. United States Dept. of the Interior, Bureau of Ocean Energy Management, Office of Renewable Energy Programs, Herndon, VA. OCS Study BOEM 2013-0010. $273 \mathrm{p}$.

Reubens, J. T., Degraer, S. and Vincx, M. 2014. The ecology of benthopelagic fishes at offshore wind farms: a synthesis of 4 years of research. Hydrobiologia. 727(1). p. 121-136.

Tetra Tech EC, Inc. (Tetra Tech). 2012. Affected Environment, Potential Impacts, and Mitigation Measures. Block Island Wind Farm and Block Island Transmission System Environmental Report/Construction and Operations Plan. Providence, RI: Deepwater Wind, LLC.

Wahlberg, M. and Westerberg, H. 2005. Hearing in fish and their reactions to sounds from offshore wind farms. Marine Ecology Progress Series. 288. p. 295-309.

Walker, T. I. 2001. Basslink project review of impacts of high voltage direct current sea cables and electrodes on chondrichthyan fauna and other marine life. Report 20 to NSR Environmental Consultants Pty Ltd. 77 p.

Wilhelmsson, D., Malm, T. and Öhman, M. C. 2006. The influence of offshore windpower on demersal fish. ICES Journal of Marine Science. 63(5). p. $775-784$. 